\title{
The Clinical and Radiographic Importance of Distinguishing Partial from Near-Complete Reperfusion Following Intra-Arterial Stroke Therapy
}

\author{
M.V. Jayaraman, J.A. Grossberg, K.M. Meisel, A. Shaikhouni, and B. Silver
}

\begin{abstract}
BACKGROUND AND PURPOSE: Reperfusion following intra-arterial stroke therapy is associated with improved clinical outcomes. However, the degree of reperfusion needed to achieve successful outcomes is unknown. The purpose of this analysis was to determine whether the degree of reperfusion has an impact on final infarct volumes and clinical outcomes.
\end{abstract}

MATERIALS AND METHODS: A retrospective analysis identified 88 consecutive patients who underwent intra-arterial therapy for acute anterior circulation stroke. Reperfusion was graded by using the $\mathrm{TICl}$ scale into none ( $\mathrm{TICI} 0$ or 1), partial ( $\mathrm{TICI} 2 \mathrm{a}$ ), or near-complete ( $\mathrm{TICl}$ $2 \mathrm{~b} / 3)$. Baseline characteristics were compared. For each of these groups, we compared discharge disposition and final infarct volumes.

RESULTS: Near-complete, partial, and no reperfusion occurred in $44.3 \%, 26.1 \%$, and $29.6 \%$ of patients, respectively. Baseline characteristics were similar across all 3 groups. The median NIHSS score was 15 . Significant differences in discharge disposition were seen, with $41.0 \%$ of the $\mathrm{TICl} 2 \mathrm{~b} / 3$ group discharged home versus $17.4 \%$ of $\mathrm{TICl} 2 \mathrm{a}$ and $7.7 \%$ of $\mathrm{TICl} 0 / 1$. In-hospital mortality was $12.8 \%$ for $\mathrm{TICl} 2 \mathrm{~b} / 3 \mathrm{compared}$ with $39.1 \%$ for $\mathrm{TICl} 2 \mathrm{a}$ and $34.6 \%$ for $\mathrm{TICl} 0 / 1$. Patients with near-complete reperfusion were significantly more likely to have infarct volumes $\leq 70$ $\mathrm{mL}(\mathrm{OR}=12.1 ; 95 \% \mathrm{Cl}, 2.7-54.2)$, compared with patients with partial reperfusion ( $\mathrm{OR}=2.2 ; 95 \% \mathrm{Cl}, 0.5-9.6)$.

CONCLUSIONS: Significant differences exist in outcomes and infarct volumes between partial ( $\mathrm{TICI} 2 \mathrm{a}$ ) and near-complete (TICI 2b/3) reperfusion following intra-arterial stroke therapy. Further trials should separately report these groups to facilitate comparison among treatment paradigms.

ABBREVIATIONS: $\mathrm{Cl}$ = confidence interval; IAT = intra-arterial thrombolysis; IMS = Interventional Management of Stroke; OR = odds ratio; $\mathrm{TICl}=$ Thrombolysis in Cerebral Ischemia; TIMI = Thrombolysis in Myocardial Ischemia

I

ntra-arterial therapy, including thrombolytic infusion and mechanical thrombectomy, has emerged during the past decade as a potential treatment option for patients with acute ischemic stroke from large-vessel occlusion who are ineligible for or fail to improve following intravenous tPA. ${ }^{1-5}$ While there is a strong association between any reperfusion and favorable clinical outcome, there is not a universal benefit to reperfusion. For example, analysis of the Mechanical Embolus Removal in Cerebral Ischemia and Multi MERCI trials showed that $48 \%$ of patients in whom reperfusion was achieved had a favorable clinical outcome, compared with $6 \%$ of nonreperfused patients. ${ }^{6}$

Received March 16, 2012; accepted after revision April 13.

From the Departments of Diagnostic Imaging (M.V.J.), Neurosurgery (M.V.J., J.A.G., A.S.), and Neurology (K.M.M., B.S.), Warren Alpert School of Medicine at Brown University, Rhode Island Hospital, Providence, Rhode Island.

Please address correspondence to Mahesh V. Jayaraman, MD, 3rd Floor, Main Building, Rhode Island Hospital, 593 Eddy St, Providence, RI 02903; e-mail: mjayaraman@lifespan.org

= Indicates article with supplemental on-line tables.

http://dx.doi.org/10.3174/ajnr.A3278
The angiographic efficacy of either IAT or mechanical thrombectomy can be described by using a variety of grading systems. The most commonly reported means is the TICI score, derived from the TIMI schema. The definition and classification have been previously described. ${ }^{7}$ Many stroke trials have considered TICI $2 / 3$ to be "successful" reperfusion and TICI $0 / 1$ to be "failed reperfusion." The TICI 2 class is further subdivided into either TICI $2 \mathrm{a}$ or $2 \mathrm{~b}$, depending on whether the residually occluded territory involves more or less than two-thirds of the vascular distribution of the initial occlusion, respectively (On-line Table 1).

While several previous studies have shown improved clinical outcomes with reperfused (defined as TICI 2/3 flow) compared with nonreperfused patients (TICI 0/1), few studies have specifically examined the relationship between TICI $2 \mathrm{a}$ and $2 \mathrm{~b} / 3$ reperfusion. The purpose of our study was to determine whether differences in clinical outcomes exist between patients in whom partial reperfusion (which we defined as TICI 2a) is achieved versus those with near-complete reperfusion (which we defined as TICI $2 b / 3$ ). We also sought to examine the relationship between reperfusion class, final infarct volume, and clinical outcome. 


\begin{tabular}{|c|c|c|c|c|c|}
\hline & \multirow[b]{2}{*}{ All Patients } & \multicolumn{3}{|c|}{ By Final TICI Class } & \multirow[b]{2}{*}{$P$ Value } \\
\hline & & $\mathrm{TICl} 0 / 1$ & $\mathrm{TICI} 2 \mathrm{a}$ & $\mathrm{TICl} 2 \mathrm{~b} / 3$ & \\
\hline No. (\%) & 88 & $26(29.6)$ & $23(26.1)$ & $39(44.3)$ & \\
\hline Age (mean) & 68.2 & 68.9 & 68.1 & 67.9 & .81 \\
\hline Sex (\% female) & $50 \%$ & $57.70 \%$ & $47.80 \%$ & $46.10 \%$ & .68 \\
\hline History of hypertension & $72.70 \%$ & $65.40 \%$ & $73.90 \%$ & $76.90 \%$ & .62 \\
\hline Diabetes mellitus & $28.40 \%$ & $26.90 \%$ & $21.70 \%$ & $33.30 \%$ & .63 \\
\hline Coronary artery disease & $25 \%$ & $30.80 \%$ & $30.40 \%$ & $17.90 \%$ & .36 \\
\hline Atrial fibrillation & $31.80 \%$ & $23.10 \%$ & $34.80 \%$ & $35.90 \%$ & .58 \\
\hline Prior ischemic stroke & $19.30 \%$ & $15.40 \%$ & $26.10 \%$ & $17.90 \%$ & .63 \\
\hline Cigarette smoking within past 12 months & $22.70 \%$ & $23.10 \%$ & $17.40 \%$ & $25.60 \%$ & .77 \\
\hline Peripheral artery disease & $9.10 \%$ & $3.90 \%$ & $8.70 \%$ & $12.80 \%$ & .58 \\
\hline Mean admission NIHSS score & 14.9 & 15.2 & 15.5 & 14.3 & .83 \\
\hline Median admission NIHSS score & 15 & 14.5 & 16 & 15 & .83 \\
\hline Admission systolic BP (mm Hg, mean) & 144.60 & 143.50 & 146.00 & 144.50 & .87 \\
\hline Admission blood glucose (mg/dL, mean) & 131.10 & 122.60 & 130.80 & 137.10 & .51 \\
\hline $\begin{array}{l}\text { Proximal occlusion (ICA or proximal Ml segment of MCA with } \\
\text { lenticulostriate involvement) }\end{array}$ & $51.10 \%$ & $57.7 \%$ & $65.2 \%$ & $38.5 \%$ & .09 \\
\hline Time from symptom onset to angiography (min, mean) & 288.80 & 302.3 & 299.6 & 272.7 & .51 \\
\hline
\end{tabular}

Note:-BP indicates blood pressure.

\section{MATERIALS AND METHODS}

Institutional review board approval was obtained for the study. The stroke center data bases at 2 teaching hospitals were reviewed for patients 18 years of age or older who underwent intra-arterial therapy (either alone or in conjunction with intravenous tPA) for acute anterior circulation ischemic stroke between January 1, 2005, and December 31, 2010. Such patients typically had admission NIHSS scores of $\geq 8$ or moderate-to-severe aphasia, initial CT findings of less than one-third MCA territory involvement with acute infarct signs such as hypoattenuation with sulcal effacement and angiographically documented occlusion (TICI 0/1) of the ICA, M1, or proximal M2 segment. Additional imaging studies (eg, CTA, diffusion MR imaging) were performed in some patients. General anesthesia was not routinely used for angiography unless the patient's clinical status necessitated airway protection. Patients were excluded if the stroke was in the posterior circulation, the event was a complication of another angiographic procedure, or angiography showed no proximal arterial occlusion (defined as TICI 0/1).

For all patients, the following demographics were recorded from a retrospective review of the medical records: age, sex, history of hypertension, diabetes mellitus, coronary artery disease, atrial fibrillation, prior stroke, cigarette smoking in the past year, peripheral artery disease, NIHSS score at admission, admission systolic blood pressure, and admission blood glucose. In some cases when a documented NIHSS score at admission could not be found in the medical record, it was extrapolated on the basis of the documented neurologic examination. ${ }^{8}$ Angiographic/treatment parameters recorded were the following: site of occlusion, time from symptom onset (or last seen well) to the start of angiography, administration of intravenous tPA, intra-arterial therapy performed (mechanical thrombectomy and/or IAT), location of arterial occlusion, and TICI status pre- and posttreatment.

TICI scoring was performed by retrospective review of angiographic images on a PACS workstation by a single interventional neuroradiologist (M.V.J.) blinded to the clinical outcome of the patient. We used the TICI score as presented in the previously published reporting standards document, ${ }^{7}$ in which TICI $2 \mathrm{a}$ would imply patent flow through the site of the initial occlusion but distal filling of less than two-thirds of the affected territory. We defined TICI $0 / 1$ as "failed reperfusion," TICI 2a as "partial reperfusion," and TICI 2 b or 3 as "near-complete reperfusion." In the TICI classification that we used (On-line Table 1), TICI 2a reperfusion implies not just recanalization of the proximal arterial branches but also washout of contrast during the angiographic run in a timely fashion, suggestive of end tissue reperfusion. For this reason, we will use the term "reperfusion" in the remainder of this article. For patients with ICA or M1 occlusion, infarct volumes on posttreatment images obtained between 24 and 48 hours after treatment were calculated by determining volumes on each axial section and multiplying by the section thickness. The presence of any hemorrhage on posttreatment imaging was recorded, and hemorrhage was classified according to the European Cooperative Acute Stroke Study definition..$^{9-11}$ Outcomes were categorized on the basis of hospital discharge status into 3 categories: home (with or without services), rehabilitation (short- or long-term), or death (including discharge to hospice care).

\section{Statistical Analysis}

All statistical analysis was performed by using R software (http:// www.R-project.org). We used the Fisher exact test for significance testing for differences between groups for categoric variables; for ordinal variables, we used the Mann-Whitney $U$ test for medians. Odds ratios were calculated for likelihood of final infarct volume $(\leq 70 \mathrm{~mL}$ ) for each of TICI $2 \mathrm{~b} / 3$, TICI $2 / 3$ (including $2 \mathrm{a}$ and $2 \mathrm{~b}$ ), and TICI 2 a alone compared with TICI $0 / 1$. Odds ratios for discharge home and in-hospital mortality were also similarly calculated. Odds ratios were calculated by using http://www.hutchon. net/ConfidOR.htm. $P$ values $<.05$ were considered significant.

\section{RESULTS}

Eighty-eight patients met the defined inclusion criteria. The mean age was 68.2 years, $50 \%$ of patients were female, and the median NIHSS score at admission was 15 (range, 2-29). The baseline characteristics of all patients and by TICI grouping are recorded 
Table 2: Treatment details of intra-arterial therapy

\begin{tabular}{lrr}
\hline \multicolumn{1}{c}{ Angiographic Parameters } & No. & $\%$ \\
\hline IV tPA given prior to IA therapy & 14 & 15.9 \\
Intubated at any point during angiography & 3 & 3.4 \\
Site of occlusion & & \\
ICA & 22 & 25.0 \\
M1, proximal (involves lenticulostriates) & 23 & 26.1 \\
M1, distal (spares lenticulostriates) & 16 & 18.2 \\
M2 & 25 & 28.4 \\
M3 & 2 & 2.3 \\
Concomitant cervical segment ICA stenosis & 16 & 18.2 \\
$\quad$ (70\%) or occlusion & & \\
Treatment & & \\
Thrombolytic infusion alone & 65 & 73.9 \\
$\quad$ Mechanical thrombectomy alone & 4 & 4.5 \\
Both MT and IAT & 19 & 21.6 \\
Intracranial stent placement & 4 & 4.5 \\
\hline
\end{tabular}

Note:-IA indicates intra-arterial; MT, mechanical thrombectomy.

Table 3: Discharge disposition by $\mathrm{TICl}$ class and infarct volume

\begin{tabular}{lcccc}
\hline & Home & Rehab & $\begin{array}{c}\text { Death/ } \\
\text { Hospice }\end{array}$ & $\begin{array}{c}\boldsymbol{P} \\
\text { Value }\end{array}$ \\
\hline All Patients & $25 \%$ & $48.9 \%$ & $26.1 \%$ & \\
By TICl class & & & & \\
$\quad \mathrm{TICl} 0 / 1$ & $7.7 \%$ & $57.7 \%$ & $34.6 \%$ & .0084 \\
$\mathrm{TICl} 2 \mathrm{a}$ & $17.4 \%$ & $43.5 \%$ & $39.1 \%$ & \\
$\mathrm{TICl} 2 \mathrm{~b} / 3$ & $41.0 \%$ & $46.2 \%$ & $12.8 \%$ & \\
By infarct volume & & & & \\
$\quad$ Infarct volume $\leq 70 \mathrm{~mL}$ & $36 \%$ & $50 \%$ & $14 \%$ & \\
$\quad$ Infarct volume $>70 \mathrm{~mL}$ & $0 \%$ & $38 \%$ & $63 \%$ & \\
\hline
\end{tabular}

Note:- Rehab indicates rehabilitation.

in Table 1. No significant differences were noted. Sixty-five patients $(73.9 \%)$ had IAT alone, $19(21.6 \%)$ had both IAT and mechanical thrombectomy, and 4 (4.5\%) had mechanical thrombectomy alone (Table 2). Intracranial stents were placed in 4 patients $(4.5 \%)$ for presumed underlying stenosis. Final thrombolysis scores were TICI 0/1 (failed reperfusion) for $29.6 \%$, TICI 2 a (partial reperfusion) for $26.1 \%$, and TICI $2 \mathrm{~b} / 3$ (near-complete reperfusion) for $44.3 \%$.

Table 3 summarizes the relationship between TICI score and outcome. Significantly more patients had better outcomes with TICI scores of $2 \mathrm{~b} / 3$ compared with $2 \mathrm{a}$. Home discharges increased from $7.7 \%$ for TICI $0 / 1$ to $17.4 \%$ for TICI 2 a to $41 \%$ for TICI $2 b / 3$ $(P=.0084)$. Mortality was significantly lower in the TICI $2 \mathrm{~b} / 3$ group compared with TICI 2 a $(12.8 \%$ versus $39.1 \%)(P=.0084)$.

Posttreatment imaging was unavailable for 1 patient who died within 24 hours of the procedure, and 27 patients had an M2 or M3 occlusion, leaving 60 patients for the imaging analysis. Mean infarct volumes based on reperfusion class were $33.7 \pm 46.3 \mathrm{~mL}$ for TICI $2 \mathrm{~b} / 3,84.8 \pm 88.3$ for TICI $2 \mathrm{~b}$, and $147.9 \pm 103.2$ for TICI $0 / 1$. Based on discharge disposition, mean final infarct volumes were $12.5 \pm 19.9 \mathrm{~mL}, 46.5 \pm 43.8 \mathrm{~mL}$, and $161.8 \pm 165 \mathrm{~mL}$ for home, rehabilitation, and death/hospice respectively. Mortality was $63 \%$ in patients with a final infarct volume $>70 \mathrm{~mL}$ compared with $14 \%$ in those with $\leq 70 \mathrm{~mL}$ (Table 3 ).

The odds ratios for smaller final infarct for different reperfusion classes are summarized in Table 4. Patients were more likely to have infarct volumes $\leq 70 \mathrm{~mL}$ with TICI $2 \mathrm{~b} / 3$ versus TICI $2 \mathrm{a}$ reperfusion (Table 4 ). When TICI $2 \mathrm{a}$ and $2 \mathrm{~b} / 3$ are all grouped together, there remains a significant likelihood that patients with
Table 4: Odds ratios for final infarct volume $<70 \mathrm{~mL}$ by final reperfusion class, compared with $\mathrm{TICl} 0 / 1$ reperfusion

OR Compared with TIC $0 / 1$ for Final Infarct

Volume $<70 \mathrm{~mL}(95 \% \mathrm{Cl})$
$\mathrm{TICl} 2 \mathrm{~b} / 3$ reperfusion

$\mathrm{TICl} 2 \mathrm{a}$ or $2 \mathrm{~b} / 3$ reperfusion

(any reperfusion)

$\mathrm{TICl} 2 \mathrm{a}$ reperfusion
$12.1(2.7-54.2)$

$6.79(1.8-25.2)$

$2.2(0.5-9.6)$
Table 5: Odds ratios for discharge home and in-hospital mortality comparing various reperfusion groups versus $\mathrm{TICI} 0 / 1$, for all patients and those with ICA and Mi occlusions only

\begin{tabular}{|c|c|c|c|c|}
\hline & \multicolumn{2}{|c|}{$\begin{array}{l}\text { All Patients } \\
\qquad(n=88)\end{array}$} & \multicolumn{2}{|c|}{$\begin{array}{l}\text { ICA, M1 Only } \\
(n=61)\end{array}$} \\
\hline & OR & $95 \% \mathrm{Cl}$ & OR & $95 \% \mathrm{Cl}$ \\
\hline \multicolumn{5}{|l|}{ OR for discharge home } \\
\hline $\mathrm{TICl} 2 \mathrm{a}$ vs $0 / 1$ & 2.52 & $(0.41-15.2)$ & $\mathrm{N} / \mathrm{A}^{\mathrm{a}}$ & \\
\hline $\mathrm{TICl} 2 \mathrm{~b} / 3$ vs $2 \mathrm{a}$ & 3.30 & (0.94-11.56) & 5.18 & (0.99-27.07) \\
\hline $\mathrm{TICl} 2 \mathrm{~b} / 3$ vs $0-2 \mathrm{a}$ & $4.99^{\mathrm{b}}$ & $(1.72-14.48)^{\mathrm{b}}$ & 10.03 & $(1.99-50.51)^{\mathrm{b}}$ \\
\hline \multicolumn{5}{|l|}{$\begin{array}{l}\text { OR for in-hospital } \\
\text { mortality }\end{array}$} \\
\hline $\mathrm{TICl} 2 \mathrm{a}$ vs $0 / 1$ & 1.21 & $(0.38-3.88)$ & 0.88 & $(0.22-3.45)$ \\
\hline $\mathrm{TICl} 2 \mathrm{~b} / 3$ vs $2 \mathrm{a}$ & $0.23^{b}$ & $(0.07-0.81)^{b}$ & 0.17 & $(0.04-0.68)^{b}$ \\
\hline $\mathrm{TICl} 2 \mathrm{~b} / 3$ vs $0-2 \mathrm{a}$ & $0.25^{\mathrm{b}}$ & $(0.08-0.76)^{b}$ & 0.16 & $(0.04-0.55)^{b}$ \\
\hline
\end{tabular}

any reperfusion will have smaller infarcts compared with those with no reperfusion, but the effect is smaller.

We also considered the possibility that patients with M2 occlusions might have a more benign clinical course than those with ICA or M1 occlusion. We compared the odds ratios for discharge home and in-hospital mortality in our entire sample and in those with ICA or M1 occlusions only; the data are summarized in Table 5. As would be expected, the difference between partial and nearcomplete reperfusion appears to be greater when M2 occlusions are eliminated from the analysis. When occlusions of M2 and beyond are removed from the analysis, the OR for discharge home with TICI $2 \mathrm{~b} / 3$ versus TICI $2 \mathrm{a}$ reperfusion almost reaches statistical significance (lower limit of $95 \%$ confidence interval, 0.99 ) and may do so with a larger sample size.

Rates of all hemorrhage on imaging were similar between the TICI $0 / 2 \mathrm{a}$ and TICI $2 \mathrm{~b} / 3$ groups ( $38.8 \%$ and $41.0 \%$, respectively). Rates of parenchymal hematoma type 2 (European Cooperative Acute Stroke Study definition) were higher with TICI 0/2a versus TICI $2 \mathrm{~b} / 3$ ( $10.2 \%$ versus $2.6 \%$ ), but this difference was not statistically significant.

\section{DISCUSSION}

In this retrospective analysis, we show that for patients presenting with acute anterior circulation stroke, complete or near-complete angiographic reperfusion (TICI $2 \mathrm{~B} / 3$ ) appears to result in significant improvement in discharge outcomes versus partial reperfusion (TICI 2a). Our patients with TICI $2 \mathrm{~b} / 3$ reperfusion had higher rates of discharge to home $(41.0 \%$ versus $17.4 \%)$, lower rates of in-hospital mortality (12.8\% versus $39.1 \%)$, and a higher percentage with $\leq 70$ - $\mathrm{mL}$ final infarct volume ( $81 \%$ versus $56 \%$ ). While other series have shown a benefit to reperfu- 
sion overall (defined as TICI 2/3), to our knowledge, this is the first study showing a significant improvement in outcomes between TICI $2 \mathrm{a}$ and $2 \mathrm{~b} / 3$ reperfusion. This would suggest that the threshold for success in intra-arterial stroke therapy for proximal large-artery occlusion is best defined as TICI $2 \mathrm{~b}$ flow or better.

An analysis of the IMS I and II trials of combined intravenous and intra-arterial therapy showed a trend toward better outcomes with TICI $2 \mathrm{a}$ versus $2 \mathrm{~b} / 3$, but this did not reach statistical significance $(P=.08) .{ }^{12}$ That analysis did show, however, that the relationship between angiographic reperfusion and good outcome was stronger for TICI $2 \mathrm{~b} / 3$ reperfusion than for TICI $2 / 3$. Differences in outcomes between partial and complete revascularization were also presented for the Middle Cerebral Artery Embolism Local Fibrinolytic Intervention Trial, ${ }^{5}$ but not by using the same TICI scale. Our threshold for near-complete was $66 \%$ of affected territory, compared with $50 \%$ for IMS I/II. It would seem intuitive that a higher degree of reperfusion would be more predictive of good clinical outcome.

There are several schema available for classifying angiographic results, including the Mori scale, ${ }^{5}$ TIMI, the arterial occlusive lesion score from IMS, and the original TICI and the modified TICI, with $2 \mathrm{a}$ and $2 \mathrm{~b}$ defined separately. The relationship between these schema and outcomes, including comparison of TIMI and Mori schemes and comparison of outcomes based on TIMI, has also been done, ${ }^{13}$ with both of those series suggesting a benefit to partial reperfusion. However, the definition of partial reperfusion is key, with TIMI 2 (encompassing both $2 \mathrm{a}$ and $2 \mathrm{~b}$ ) considered partial reperfusion in both of those series. Our data would suggest that the distinction between partial and near-complete reperfusion should be made at the TICI $2 \mathrm{a} / 2 \mathrm{~b}$ level.

In a recently published analysis of the MERCI and Multi MERCI trials, Fields et $\mathrm{al}^{14}$ showed increases in favorable clinical outcomes and decreases in mortality with increasing rates of TIMI recanalization. In our series, we combined TICI 0/1 grades as "no reperfusion," as has been done in almost all previous trials of intra-arterial therapy. Another important issue is whether further revascularization attempts should be pursued when TICI 2a reperfusion has been achieved. It is conceivable that further attempts, especially with mechanical devices, to reperfuse distal branches once TICI 2 a reperfusion has been achieved may be deleterious to the patient.

Our results evaluating the relationship of final infarct volume with reperfusion class and outcomes are concordant with recent data showing a relationship between volume of infarct core at arrival to the hospital and clinical outcomes. Yoo et $\mathrm{al}^{15}$ showed that for patients undergoing intra-arterial therapy, a baseline diffusion-weighted infarct volume of $70 \mathrm{~mL}$ predicted poor outcome, irrespective of reperfusion. Similar data have also been shown for the Echoplanar Imaging Thrombolysis Evaluation Trial, by using extended-time-window treatment with IV tPA, with a cutoff of $65 \mathrm{~mL}$, beyond which intravenous tPA appeared to be harmful, with the greatest benefit seen for patients with DWI lesions $<25 \mathrm{~mL} .{ }^{16}$ Another extended-time-window trial, the Diffusion and Perfusion Imaging Evaluation for Understanding Stroke Evolution trial, also showed that patients with an admission DWI lesion of $>100 \mathrm{~mL}$ did poorly even with reperfusion. ${ }^{17}$
It appears from our data that clinical outcomes in patients with final infarct volumes $>70 \mathrm{~mL}$ are poor, with a $63 \%$ in-hospital mortality. Our results would suggest that in patients with proximal large-artery occlusion (ICA, M1), most of the territory would need to be salvaged to minimize final infarct volume and thus offer the greatest possible clinical benefit.

Despite some increases in reperfusion rates from intra-arterial prourokinase administration to mechanical thrombectomy, patient outcomes have not improved at the same rate. Many trials of IAT have not separately reported TICI 2 a versus $2 \mathrm{~b}$ reperfusion, and this omission may partially explain the lack of improved clinical outcomes, despite increasing published rates of reperfusion. In On-line Table 2, we summarize major multicenter studies of IAT. Most of these studies do not separate reperfusion into partial (TICI 2a) versus complete (TICI 2b/3).

This study has limitations. First, it is a retrospective singlecenter study. Second, patient selection and treatment protocols were not precisely defined as they are for prospective trials. Nevertheless, baseline demographics in this study are similar to those in other trials, and reperfusion results were similar to those in several multicenter trials (On-line Table 2). Third, 90-day outcomes were not available for most patients, and outcome status was based on discharge location. Discharge disposition has been used as an outcome marker in previously published studies of intra-arterial therapy for stroke. ${ }^{18}$ In addition, our study included patients with an NIHSS $<10$, and patient outcomes (regardless of treatment) are generally better with lower admission NIHSS scores.

Future studies of intra-arterial therapy should separate angiographic results into none, partial (TICI 2a), and near-complete (TICI $2 b / 3$ ). Clinical outcomes should be reported separately for these groups. Both our results and those from IMS I and II have shown that the greatest benefit appears to be for the near-complete reperfusion group, though different thresholds were used (66\% for near-complete in this study and $50 \%$ for near-complete in IMS I/II). While the optimal degree of reperfusion necessary to be considered successful may not yet be determined, it seems that including patients with low degrees of reperfusion $(<50 \%)$ in the "success" group may overstate the angiographic results of intraarterial therapy. If indeed the outcome of therapy needs to be dichotomized, perhaps angiographic success from intra-arterial therapy should be defined as TICI $2 \mathrm{~b} / 3$ reperfusion. It may also be beneficial for all multicenter trials to have angiographic core lab evaluation because local angiographers can overgrade their outcomes. ${ }^{19}$ Analysis of ongoing and future multicenter trials may allow us to further refine the TICI 2 subcategories and help determine the optimal threshold to be considered successful. We hope that newer therapies will allow rapid achievement of complete reperfusion in a greater percentage of patients, with the expectation that complete reperfusion translates into better outcomes for our patients.

\section{CONCLUSIONS}

Significant differences exist in clinical outcomes between partial (TICI 2a) and near-complete (TICI 2b/3) reperfusion following intra-arterial stroke therapy for acute anterior circulation stroke. 
Further trials should separately report these groups to facilitate comparison among treatment paradigms.

Disclosures: Mahesh Jayaraman—UNRELATED: Consultancy: DePuy Institute, Comments: 1-time consulting fee for feedback on physician education programs. Brian Silver-UNRELATED: Consultancy: Abbott Vascular, Expert Testimony: Hackney, Grover, Hoover \& Bean; Hill, Adams, Hall \& Schieffelin, P.A., Comments: medical malpractice defense, Other: authorship royalties for MedLink, Medscape, and Oakstone Publishing.

\section{REFERENCES}

1. Furlan A, Higashida $\mathrm{R}$, Wechsler L, et al. Intra-arterial prourokinase for acute ischemic stroke: the PROACT II study: a randomized controlled trial-Prolyse in Acute Cerebral Thromboembolism. JAMA 1999;282:2003-11

2. del Zoppo GJ, Higashida RT, Furlan AJ, et al. PROACT: a phase II randomized trial of recombinant pro-urokinase by direct arterial delivery in acute middle cerebral artery stroke-PROACT Investigators. Prolyse in Acute Cerebral Thromboembolism. Stroke 1998;29:4-11

3. Flint AC, Duckwiler GR, Budzik RF, et al. Mechanical thrombectomy of intracranial internal carotid occlusion: pooled results of the MERCI and Multi MERCI Part I trials. Stroke 2007;38:1274-80

4. Penumbra Pivotal Stroke Trial Investigators. The Penumbra Pivotal Stroke Trial: safety and effectiveness of a new generation of mechanical devices for clot removal in intracranial large vessel occlusive disease. Stroke 2009;40:2761-68

5. Ogawa A, Mori E, Minematsu K, et al. Randomized trial of intraarterial infusion of urokinase within 6 hours of middle cerebral artery stroke: the middle cerebral artery embolism local fibrinolytic intervention trial (MELT) Japan. Stroke 2007;38:2633-39

6. Nogueira RG, Liebeskind DS, Sung G, et al. Predictors of good clinical outcomes, mortality, and successful revascularization in patients with acute ischemic stroke undergoing thrombectomy: pooled analysis of the Mechanical Embolus Removal in Cerebral Ischemia (MERCI) and Multi MERCI Trials. Stroke 2009;40: 3777-83

7. Higashida RT, Furlan AJ, Roberts $H$, et al. Trial design and reporting standards for intra-arterial cerebral thrombolysis for acute ischemic stroke. Stroke 2003;34:e109-137

8. Kasner SE, Cucchiara BL, McGarvey ML, et al. Modified National Institutes of Health Stroke Scale can be estimated from medical records. Stroke 2003;34:568-70

9. Berger C, Fiorelli M, Steiner T, et al. Hemorrhagic transformation of ischemic brain tissue: asymptomatic or symptomatic? Stroke 2001;32:1330-35

10. Fiorelli M, Bastianello S, von Kummer R, et al. Hemorrhagic transformation within 36 hours of a cerebral infarct: relationships with early clinical deterioration and 3-month outcome in the European Cooperative Acute Stroke Study I (ECASS I) cohort. Stroke 1999;30:2280-84

11. Hacke W, Kaste M, Fieschi C, et al. Intravenous thrombolysis with recombinant tissue plasminogen activator for acute hemispheric stroke: the European Cooperative Acute Stroke Study (ECASS). JAMA 1995;274:1017-25

12. Tomsick T, Broderick J, Carrozella J, et al. Revascularization results in the Interventional Management of Stroke II Trial. AJNR Am J Neuroradiol 2008;29:582-87

13. Arnold M, Nedeltchev K, Remonda L, et al. Recanalisation of middle cerebral artery occlusion after intra-arterial thrombolysis: different recanalisation grading systems and clinical functional outcome. J Neurol Neurosurg Psychiatry 2005;76:1373-76

14. Fields JD, Lutsep HL, Smith WS. Higher degrees of recanalization after mechanical thrombectomy for acute stroke are associated with improved outcome and decreased mortality: pooled analysis of the MERCI and Multi MERCI Trials. AJNR Am J Neuroradiol 2011;32:2170-74

15. Yoo AJ, Verduzco LA, Schaefer PW, et al. MRI-based selection for intra-arterial stroke therapy: value of pretreatment diffusionweighted imaging lesion volume in selecting patients with acute stroke who will benefit from early recanalization. Stroke 2009; 40:2046-54

16. Parsons MW, Christensen S, McElduff $P$, et al. Pretreatment diffusion- and perfusion-MR lesion volumes have a crucial influence on clinical response to stroke thrombolysis. J Cereb Blood Flow Metab 2010;30:1214-25

17. Albers GW, Thijs VN, Wechsler L, et al. Magnetic resonance imaging profiles predict clinical response to early reperfusion: the diffusion and perfusion imaging evaluation for understanding stroke evolution (DEFUSE) study. Ann Neurol 2006;60:508-17

18. Shaltoni HM, Albright $\mathrm{KC}$, Gonzales NR, et al. Is intra-arterial thrombolysis safe after full-dose intravenous recombinant tissue plasminogen activator for acute ischemic stroke? Stroke 2007;38: $80-84$

19. Tomsick T. TIMI, TIBI, TICI: I came, I saw, I got confused. AJNR Am J Neuroradiol 2007;28:382-84

20. Smith WS, Sung G, Saver J, et al. Mechanical thrombectomy for acute ischemic stroke: final results of the Multi MERCI trial. Stroke 2008;39:1205-12

21. Lewandowski CA, Frankel M, Tomsick TA, et al. Combined intravenous and intra-arterial r-TPA versus intra-arterial therapy of acute ischemic stroke: Emergency Management of Stroke (EMS) Bridging Trial. Stroke 1999;30:2598-605

22. IMS II Trial Investigators. The Interventional Management of Stroke (IMS) II Study. Stroke 2007;38:2127-35 